\title{
The detection of SARS-CoV-2 using Reverse Transcription Loop-Mediated Isothermal Amplification (RT-LAMP) in developing country
}

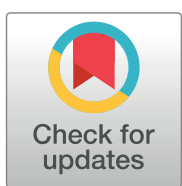

\author{
Muhammad Rizky Wibowo', Erna Harfiani $\mathbb{B}^{1}$, Sarmoko $\mathbb{B}^{2}$, Yudhi Nugraha $\mathbb{(}^{1 *}$ \\ 'Faculty of Medicine, Universitas Pembangunan Nasional Veteran Jakarta, Jl. R.S Fatmawati No. 1, Jakarta Selatan 12450, Indonesia. \\ ${ }^{2}$ Department of Pharmacy, Faculty of Health Sciences, Jenderal Soedirman University, Indonesia. JI Dr. Soeparno Karangwangkal, \\ Purwokerto, Central Java 53123, Indonesia. \\ ${ }^{*}$ Corresponding author: Jl. R.S Fatmawati No. 1, Jakarta Selatan 12450, Indonesia. E-mail: ynugraha@upnvj.ac.id
}

\begin{abstract}
The severe acute respiratory syndrome coronavirus (SARS-CoV-2) has infected the human system resulting in Covid-19, and has spread rapidly worldwide. Therefore, a fast, simple, cost-effective, and accurate detecting tool is required. The standard diagnostic tool of the World Health Organization is the reverse transcription-polymerase chain reaction (RT-PCR). This method detects the presence of viral genetic material in the human body with accurate results. However, it has several limitations in terms of equipment, personnel, duration, and cost. Therefore, a fast, simple, and sensitive alternative detection, is required, one of which is the reverse transcription loop-mediated isothermal amplification (RT-LAMP) that functions under isothermal conditions. This method is battery-driven, hence, easy to move closer to the patient. Conclusively, the RT-LAMP test for SARSCoV-2 diagnosis produces comparable sensitivity to a standard RT-PCR and is more suitable for resource-poor settings, such as rural areas of developing countries.
\end{abstract}

Keywords: sars-cov-2, rt-lamp, reverse transcription loop-mediated isothermal amplification

\section{Introduction}

At the end of 2019, a new type of virus that infects the human system was discovered and named Severe Acute Respiratory Syndrome Coronavirus-2 (SARS$\mathrm{CoV}-2$ ) by the World Health Organization, and the associated disease was named coronavirus disease 2019 (Covid-19) [1]. The first case was reported in Wuhan, China, and became a pandemic with a broad spectrum of impact in health, geopolitics, economy, and socio-culture. This virus infects the human respiratory system and causes mild symptoms or severe lung infections, and even death. They attack various populations such as geriatrics, adults, children, and infants, as well as pregnant women and breastfeeding mothers. Individuals with weak immunity or who possess a comorbid disease such as diabetes and hypertension are more vulnerable to the attacks [2].

SARS-CoV-2 has spread worldwide at an astonishing speed, consequently, the World Health Organization declared this a global pandemic. On the other hand, Indonesia has declared Covid-19 as a public health emergency that needs to be prevented and controlled. The country's Taskforce for the Acceleration of Handling Covid-19 reported 2.8 million confirmed cases until mid-July 2021, with a death toll of 73,582 people. Furthermore, the world's number of confirmed positive cases until mid-July 2021 is 191 million people, with a death toll of 4.1 million people. This implies that the virus is highly contagious and has spread to nearly all countries, including Indonesia. The virus is transmitted through small droplets from the nose or mouth when coughing or sneezing [3].

\section{Methods}

This study was a narrative review, which adopted PRISMA-P (Preferred Reporting Items for Systematic Reviews and Meta-Analyses Protocols) method [4]. The inclusion criteria include articles that discussed RT-LAMP or RT-PCR as a diagnostic for SARSCoV-2. The exclusion criteria are non-English articles published before 2019, and the results were organized using the Sciwheel application. 


\section{Results and discussion}

Reverse Transcription-Polymerase Chain Reaction (RT-PCR)

The reverse transcription-polymerase chain reaction is a laboratory technique used to detect the presence of genetic material present in cells and bacteria, including SARS-CoV-2. The material genetic of SARS-CoV-2 is a type of RNA virus, therefore, it needs to be converted into DNA using the reverse transcriptase enzyme into CDNA, using the reverse transcription process. The RTPCR is known to detect the existence of RNA viral genetic material in the human body with accurate results [5].

Currently, the RT-PCR tests for Covid-19 generally use a sample of mucus, phlegm, or nasopharynx fluid (the passage between nose and throat) and oropharynx (the passage between mouth and throat). The swab sample is placed into a plastic tube and sent to the laboratory for examination. During mobilization, viral RNA can be degraded under inappropriate storage conditions. Afterward, the sample will be processed and converted into cDNA and was amplified using a thermocycler, with in vitro replication principle at a temperature of $50^{\circ} \mathrm{C}$ to $96^{\circ} \mathrm{C}$. Furthermore, the examination of RT-PCR is highly dependent on trained personnel, and when PCR detects virusspecific sequences through the attachment of certain primers, then the test result is positive [5].

The Rutgers Clinical Genomics Laboratory developed the RT-PCR test (TaqPath COVID-19 Combo kit) from saliva samples collected from patients. This type of sampling is faster, less painful, reduces transmission risk for healthcare providers, and enables more sample tests [6]. The requirement for saliva-based sample includes patient who does not eat, drink, brush their teeth 30 minutes before sampling, and gargle with mouthwash in the previous two hours [7].

\section{Reverse Transcription Loop-Mediated Isothermal Amplification (RT-LAMP)}

RT-LAMP is a fast, simple, and sensitive RNA detection method performed under isothermal conditions by taking nasal swab samples [5]. Several studies have also used samples in the form of serum, stool, or eye secretions [8-10]. Furthermore, the RT-LAMP method requires a constant temperature of $60^{\circ} \mathrm{C}$ for $30-60$ minutes using simple equipment such as an incubator, water bath, or heat block. Both the positive and negative indicators are visible to the naked eye from the discoloration in the sample [11].

The RT-LAMP test overcomes the high cost associated with the RT-PCR test without losing the function of detecting nucleic acids from pathogens and also has several other advantages. A welloptimized LAMP test shows comparable sensitivity to PCR and due to its high amplification efficiency, the changes in the reaction mixture components allow the detection of the result by colorimetric methods. This indicates that high throughput tests can be performed using unrefined specimens combined with a noninstrumental detection such as colorimetry [12].

\section{RT-PCR vs RT-LAMP}

The RT-PCR method shows a high degree of accuracy, sensitivity, specificity, and reliability. Compared to the RT-LAMP, the method has been used for a long time, therefore, sufficient information regarding usage optimization for various types of diagnostic needs is available. However, this method is difficult to apply widely because of equipment, personnel, duration, and cost constraints [6,11]. Furthermore, the RT-PCR test requires a thermocycler that uses stable electrical power and a long testing time, about 1.5 to 2 hours, when performed with sophisticated equipment and by highly trained personnel to detect viral RNA viruses [12]. One of the problems associated with this method for developing countries is the unavailability of reagents, which must be imported from other countries.

Conversely, the RT-LAMP method does not require a viral RNA extraction step to diagnose the SARS$\mathrm{CoV}-2$ virus. The advantage of the RT-LAMP method is the use of a simple tool, does not require stable electrical power, and even uses batteries, which makes it easier to use. Furthermore, the potential risk of viral RNA degradation is minimal because the sample does not need to be transported to the laboratory [5]. The RT-LAMP method also has simple operation and low technical requirements for operators [13]. This method can reach areas with minimum infrastructure and help accelerate the tracing and testing stages of the SARSCoV-2 examination.

The colorimetric detection method can be used to further improve the RT-LAMP reaction reliability. Consequently, a test was performed at $63^{\circ} \mathrm{C}$ temperature for 50 minutes on a thermocycler or in water bath, and monitored by using fluorescent dyes [12]. In this case, the discoloration of dye from red to orange-yellow 
Table 1. Comparison of RT-LAMP and RT-PCR methods

\begin{tabular}{|c|c|}
\hline RT-PCR & RT-LAMP \\
\hline High level of accuracy and WHO gold standard diagnostic & A comparable level of accuracy \\
\hline $\begin{array}{l}\text { Established technology, has an adequate research } \\
\text { background }\end{array}$ & $\begin{array}{l}\text { Lack of suficient data and research background due to } \\
\text { relatively new technology }\end{array}$ \\
\hline $\begin{array}{l}\text { Samples are subjected to rapidly changing temperatures, } \\
\text { requiring a thermocycler, laboratory-grade facility with a } \\
\text { stable supply of electricity }\end{array}$ & $\begin{array}{l}\text { Samples are subjected to constant temperatures, requiring } \\
\text { only simple tools such as an incubator, water bath, or heat } \\
\text { block }\end{array}$ \\
\hline Expensive equipment & Affordable equipment \\
\hline Take a long time to get the result & The result is obtained within one hour \\
\hline Relatively high cost per test & Relatively low cost per test \\
\hline Require highly skilled personnel to perform the test properly & Does not require highly skilled personnel \\
\hline $\begin{array}{l}\text { Traditional reagents dependencies (from overseas) which } \\
\text { often in short supply during pandemics }\end{array}$ & No dependency on traditional reagents \\
\hline Difficult to apply in low-income developing countries & Easy to apply in low-income developing countries \\
\hline
\end{tabular}

indicates a positive reaction. The main mixture of a $\mathrm{pH}-$ sensitive indicator dye (cresol red) was evaluated for the detection of RT-LAMP-based SARS-CoV-2 [14]. The RT-LAMP does not rely on complex reagent kits [15], therefore it can be supplied from within the country, enabling easy application in developing countries.

The disadvantage of the RT-LAMP method for detecting SARS-CoV-2 is the change in color or cloudiness of clinical samples, which are sometimes unclear. In contrast, RT-PCR has quantitative values expressed in CT values. Therefore, its disadvantage can be resolved by using an application to read color intensity, which is converted into more quantitative data. RT-LAMP method is a relatively new technology compared to RT-PCR, hence, the research data in the diagnostic application is still insufficient. Furthermore, this method is in the clinical trial stage and needs further research development. Conclusively, early detection of SARSCoV-2 is an effective countermeasure to prevent the transmission of the virus. Therefore, developing a fast, simple, cost-effective, and accurate RT-LAMP test for the diagnosis of SARS-CoV-2 is a top priority.

\section{Conclusion}

The RT-LAMP method can be used to detect the SARS-CoV-2 using simple equipment, with a comparable high level of accuracy to the RT-PCR. It also possesses the potential to be applied in low resources health facilities.

\section{Acknowledgment}

None.

\section{Author contributions}

MRW: conceptualization, investigation, resource, and data curation. EH: curation of analysis and writing-editing, supervision, S: resource, investigation, analysis the data, finishing the original draft, YN: the idea, conceptualization, investigation, analysis the data, editing the original draft. All authors have read the final manuscript and agreed for this submission.

Received: 14 July 2021

Accepted: 25 July 2021

Published online: 31 August 2021

\section{References}

1. Lai C-C, Shih T-P, Ko W-C, Tang H-J, Hsueh P-R. Severe acute respiratory syndrome coronavirus 2 (SARS-CoV-2) and coronavirus disease-2019 (COVID-19): The epidemic and the challenges. Int J Antimicrob Agents. 2020;55: 105924. doi:10.1016/j.ijantimicag.2020.105924

2. Ejaz H, Alsrhani A, Zafar A, Javed H, Junaid K, Abdalla $\mathrm{AE}$, et al. COVID-19 and comorbidities: Deleterious impact on infected patients. J Infect Public Health. 2020;13: 1833-1839. doi:10.1016/j.jiph.2020.07.014

3. Jayaweera M, Perera H, Gunawardana B, Manatunge J. Transmission of COVID-19 virus by droplets and aerosols: A critical review on the unresolved dichotomy. Environ Res. 2020;188: 109819. doi:10.1016/j.envres.2020.109819 
4. Moher D, Shamseer L, Clarke M, Ghersi D, Liberati A, Petticrew M, et al. Preferred reporting items for systematic review and meta-analysis protocols (PRISMA-P) 2015 statement. Syst Rev. 2015;4: 1. doi:10.1186/2046-4053-4-1

5. Yoshikawa R, Abe H, Igasaki Y, Negishi S, Goto H, Yasuda J. Development and evaluation of a rapid and simple diagnostic assay for COVID-19 based on loop-mediated isothermal amplification. PLoS Negl Trop Dis. 2020;14: e0008855. doi:10.1371/journal.pntd.0008855

6. Thompson D, Lei Y. Mini review: Recent progress in RT-LAMP enabled COVID-19 detection. Sensors and Actuators Reports. 2020;2: 100017. doi:10.1016/j. snr.2020.100017

7. Salsabilah A, Nugraha Y, Pramono AP, Tjang YS. Potential Implication of Saliva-Based Molecular Diagnostic in SARS-CoV-2. Seminar Nasional Riset Kedokteran. 2021;

8. Chen C, Gao G, Xu Y, Pu L, Wang Q, Wang L, et al. SARS-CoV-2-Positive Sputum and Feces After Conversion of Pharyngeal Samples in Patients With COVID-19. Ann Intern Med. 2020;172: 832-834. doi:10.7326/M20-0991

9. Xia J, Tong J, Liu M, Shen Y, Guo D. Evaluation of coronavirus in tears and conjunctival secretions of patients with SARS-CoV-2 infection. J Med Virol. 2020;92: 589-594. doi:10.1002/jmv.25725

10. COVID-19 Investigation Team. Clinical and virologic characteristics of the first 12 patients with coronavirus disease 2019 (COVID-19) in the United States. Nat Med. 2020;26: 861-868. doi:10.1038/s41591-020-0877-5
11. Park G-S, Ku K, Baek S-H, Kim S-J, Kim SI, Kim B-T, et al. Development of Reverse Transcription Loop-Mediated Isothermal Amplification Assays Targeting Severe Acute Respiratory Syndrome Coronavirus 2 (SARSCoV-2). J Mol Diagn. 2020;22: 729-735. doi:10.1016/j. jmoldx.2020.03.006

12. Lu R, Wu X, Wan Z, Li Y, Jin X, Zhang C. A Novel Reverse Transcription Loop-Mediated Isothermal Amplification Method for Rapid Detection of SARS-CoV-2. Int J Mol Sci. 2020;21. doi:10.3390/ijms21082826

13. Li C, Ren L. Recent progress on the diagnosis of 2019 Novel Coronavirus. Transbound Emerg Dis. 2020;67: 1485-1491. doi:10.1111/tbed.13620

14. Schellenberg JJ, Ormond M, Keynan Y. Extraction-free RT-LAMP to detect SARS-CoV-2 is less sensitive but highly specific compared to standard RT-PCR in 101 samples. J Clin Virol. 2021;136: 104764. doi:10.1016/j. jcv.2021.104764

15. Fowler VL, Armson B, Gonzales JL, Wise EL, Howson ELA, Vincent-Mistiaen Z, et al. A highly effective reversetranscription loop-mediated isothermal amplification (RTLAMP) assay for the rapid detection of SARS-CoV-2 infection. J Infect. 2021;82: 117-125. doi:10.1016/j. jinf.2020.10.039 